\title{
PREPARAÇÃO DE RECURSOS VISUAIS POR COMPUTADOR
}

A.B.Macedo

A má qualidade dos recursos visuais utilizados na apresentação de trabalhos em eventos técnicos e científicos só é ultrapassada peia daqueles usados em auia. Textos e ilustrações ilegiveis; excesso de informações num mesmo quadro; tabelas intermináveis e outras barbaridades são impostas aos participantes de congressos e seminários, e, com requintes de perversidade, aos alunos.

É possivel fazer bons recursos visuais sem computador. Algumas simples regras, expressas em manuais como os de Rust \& Vermaak (1978) e Vianna et al. (1987), aplicadas com equipamento e materiais de baixo custo, permitem fazer transparências e slides de alta qualidade, se houver habilidade para tanto, ou pelo menos legíveis, por qualquer pessoa. O computador permite que isto seja feito de forma mais rápida, fácil, barata e de melhor qualidade, diminuindo as exigências de habilidade para uma apresentação agradável e eficiente.

Neste mini-curso são apresentadas as regras básicas para confecção de slides, transparências e apresentações em tela de computador e os programas que ajudam a elaborá-los: processadores de texto (Microsoft Word v.5 e para Windows), planilha (Quattro Pro), de desenho (Paintbrush e Photostyler) e de montagem de apresentações (Powerpoint).

Adaptando livremente as regras dos manuais citados, mais a dura experiência, para fazer transparências e slides. (em computador-ou cartazes para fotografar) deve-se seguir as orientações seguintes:

Formato e tamanho: o tamanho máximo para transparências é de $19 \times 23 \mathrm{~cm}$; para alguns projetores, telas e salas, nem isto, pois as bordas poderão ser projetadas fora da tela. Por segurança é melhor deixar pelo menos um centímetro de cada lado, chegando a um tamanho prático máximo de $17 \times 21 \mathrm{~cm}$. É melhor o formato horizontal (landscape) que o vertical (portrait). Se a imagem é bem menor que isto, amplie em xerox ou no computacior; se for impossível, faça uma máscara em volta da imagem, pois a grande área vazia iiuminada dificulta a visualização e dá sono. Use moldura de cartolina para transparência; melhora a aparência e facilita a organização e exibição.

Letras: o tamanho mínimo prático é de $5 \mathrm{~mm}$, com grossura $0,5 \mathrm{~mm}$ e espaçamento mínimo de $1 \mathrm{~mm}$ (aproximadamente corpo 20, maiúscula, em negrito). Use de preferência MAIÚSCULAS, não inclinadas, em letras retas (sans serif). Como você já deve estar

Departamento de Geologia Econômica e Geofísica Aplicada, Instituto de Geociências, USP. 
cansado de ver, letras datilografadas não servem para transparências. Em caso de total emergência, use apenas maiúsculas, em espaço dois, e programe mais tempo para fazer decentemente da próxima vez. Caso goste de matemática, calcule o tamanho mínimo da letra pela fórmula (Rust \& Vermaak, 1978):

$$
H=0,00262 \times C \times A / P \text {, onde: }
$$

$\mathbf{H}=$ altura em milímetros da menor letra na transparência;

C = dimensão máxima em milímetros do diagrama total (desenho e letras);

$A$ = distância da tela ao último ouvinte no auditório, em metros;

$\mathbf{P}$ = largura da tela em metros.

Informações: cada informação deve ser apresentada num diagrama separado. Cada diagrama deve ter no máximo 30 palavras ou números. Para conseguir isto, resuma o que vai ser apresentado a palavras-chave (diga as informações completas durante a apresentação oral).

Tabelas e gráficos: prefira sempre apresentar dados numéricos em gráficos que tabelas; se for impossivel, refaça as tabelas colocando apenas os números cruciais, os que mostram variação, etc. NUNCA copie uma grande tabela de onde vai usar apenas alguns dados. Os números são sempre áridos; não piore as coisas dificultando sua visualização (o que é comum demais).

Desenhos: simplifique, simplifique, simplifique. Redesenhe os mapas e gráficos colocando apenas as informações e legendas mais importantes, em traços grossos e letras tão grandes quanto dos diagramas de texto. Em caso de poucos recursos, é melhor uma transparência ou matriz para slide feito a mão, simplificado, que uma foto (ou pior, transparência xerox) de um mapa com centenas de informações invisíveis e indigeríveis.

Cores: as canetas de transparência são multicoloridas. Evite a tentação de misturar muitas cores. Use um tom neutro (preferivelmente preto) para o texto e poucas cores para sublinhar e apontar pontos mais importantes. O mesmo se aplica se fizer com impressora colorida. Se não tiver, pode fazer a transparência preto-e-branco em máquina xerox ou $3 \mathrm{M}$ e usar canetas para sublinhar a cores e/ou adesivos coloridos.

Assuntos: prefira colocar em transparências e slides dados originais (fotos, diagramas de campo), figuras, desenho; use menos números, gráficos áridos, palavras. Em geral os assuntos e ilustrações são em número muito maior que o necessário. Organize a palestra a partir de uma ou poucas sentenças que sintetizem o que tem a dizer; introduza as ilustrações aos poucos e teste o tempo. Nunca ultrapasse $70 \%$ do tempo marcado para uma apresentação, pois a abertura, a ligação dos projetores e os naturais problemas se encarregarão de gastar o resto.

Uso de computador: o computador pode ser usado para fazer matrizes para transparências e slides. As transparências podem ser impressas diretamente em impressoras mono ou policromáticas; os slides podem ser fotografados da tela, fotografados de cartazes ou produzidos diretamente em máquinas especiais, das quais o CCE tem uma, que pode ser usada pelos docentes da USP. 
Os programas podem ser mais ou menos complicados, mas devem ter a capacidade de combinar textos com fontes de tamanhos variáveis e desenhos. Os processadores de texto mais modernos (Microsoft Word for Windows, AmiPro, mesmo GeosWrite) têm esta capacidade. Gráficos quantitativos são melhor elaborados em programas de planilhas eletrônicas, como o Quattro Pro.

As regras para elaboração de recursos visuais em computador são as mesmas do trabalho manual; os programas permitem fazer um trabalho limpo, se não artístico, por qualquer pessoa. Os programas especfficos para preparação de apresentações tornam ainda mais fácil e produtivo este trabalho. Eles permitem partir de um núcleo de idéias, desenvolvê-las em texto, acrescentar ilustrações, mudar a ordem, testar seqüências, etc, em tudo mantendo coerência gráfica de um diagrama para outro. $O$ formato pode variar, havendo dezenas de escolhas num programa como Microsoft Powerpoint.

Neste curso são apresentados exemplos de bons (e maus) recursos visuais e como elaborá-los na prática, usando os programas disponfveis a todos os membros do IG-USP.

\section{REFERÊNCIAS BIBLIOGRÁFICAS}

RUST, J.C. \& VERMAAK C.F. (1978) Speaker's Guide - Hints, suggestions and instructions to speakers at symposia and congresses of the Geological Society of South Africa. s.l., Geol. Soc. South Africa, $13 \mathrm{p}$.

VIANNA, A.R.; ARARIPE, P.T.; JOBIM, L.D.C. (1987) Preparação de Transparências e Técnicas de Uso de Retroprojetor. Rio de Janeiro, DEPEX-PETROBRÁS, 25 p. 